\title{
The Influence that the Blend Process has on the Hardening Behavior of a PU/Epoxy Resin System
}

\author{
Hsien-Tang Chiu' ${ }^{1 *}$, Xiao-Yong Hsu', Hui-Min Yang ${ }^{1}$, Ya-Ting $\mathrm{Yu}^{2}$ and Yu-Sian $\mathrm{Ciou}^{2}$
}

${ }^{1}$ Department of Materials Science and Engineering, National Taiwan University of Science and Technology, Taipei, Taiwan ${ }^{2}$ Department of Testing and Certification, Taiwan Textile Research Institute, New Taipei, Taiwan

\begin{abstract}
To address the future needs of anisotropic conductive film (ACF) applications, a system that enables rapid hardening and prolongs the shelf life of ACFs was developed. In this study, various processing methods and conditions were employed to fabricate microcapsules. Imidazole was used as a hardener for epoxy resin, which was then identified and analyzed using Fourier transform infrared spectroscopy. The latent hardening behavior of microcapsules was examined using differential scanning calorimetry. Thermomechanical analysis and a peeling test were employed to analyze the thermal properties and adhesion. When coated with microcapsules, the hardener reacts to epoxy resin for a longer time. Latent hardeners with differing reaction rates can be prepared by selecting varying shell materials.
\end{abstract}

Keywords: Blend process; PU/Epoxy resin; Microencapsulation

\section{Introduction}

Anisotropic conductive films (ACFs) are composed of resin, conductive particles, and release films. Employed for their thinning ability, simple manufacturing procedure, environmentally-friendly lead-free production process, absence of a-particles, and favorable damp-proof, adhesive, conductive, and insulating functions, ACFs are mainly used to bond two substrates and circuits. Furthermore, ACFs are conductive vertically ( $\mathrm{Z}$ axis) and insulative horizontally ( $\mathrm{X}$ and $\mathrm{Y}$ axes). When the difference between the on-state resistance along the $\mathrm{Z}$ axis and the insulation resistance of the $\mathrm{XY}$ plane exceeds a certain degree, excellent anisotropic conductivity is attained. The conductive principle refers to the use of conductive particles to connect electrodes of the integrated circuit (IC) chip and the liquid crystal display (LCD) substrate, where only the current is allowed to travel along the $\mathrm{Z}$ axis and short circuits are prevented from occurring at neighboring electrodes.

The ACF material is the B-stage (partially cured) film coating formed by adding and evenly distributing a certain amount of conductive powder in the organic resin material (commonly the epoxy resin system). The primary functions of resin are damp proofing, adhesion, thermal resistance, and insulation. Resin can be roughly categorized as thermoplastics and thermosetting polymers, which include the commonly-employed styrene-butadiene rubber (SBR), acrylate, epoxy, polyamide-imide (PAI), polyimide (PI), polyetherimide (PEI), and polyurethane (PU). B-stage ACF is pressurized and heated at the hardening temperature for a certain period to attain the $\mathrm{C}$-stage (fully cured) insulation material. After the ACF is cured, the relative positions and deformation of the internal conductive particles are fixed. The cured material can also be used as an under fill to protect the internal electrodes.

When an ACF is attached to the IC bump and substrate circuit, adequate pressure, temperature, and time enable the material to begin flowing, resulting in contact between the conductive powder and the bump, which causes the substrate circuit to form electrical conduction. Simultaneously, suitable amounts of conductive powder with an appropriate particle diameter are selected to prevent contact between bumps, thereby achieving anisotropic conductivity.
Because epoxy resin possesses a high glass transition temperature $\left(\mathrm{T}_{\mathrm{g}}\right)$ and lacks toughness, epoxy products tend to have disadvantages, such as brittleness, a tendency to peel, and poor impact resistance. The introduction of small-molecule liquid crystals is expected to reinforce the mechanical strength of the product, which has been investigated in numerous studies. For example, a number of scholars have used nanoscale fillers to reinforce the mechanical strength and toughness of epoxy resin. Scholars have reformed epoxy resin using the copolymer method by introducing the soft segment into epoxy resin or directly reforming epoxy resin. By introducing the liquid crystal structure, epoxy resin can possess liquid crystal behavior that increases its mechanical strength and thermal stability. Among the various reformation methods, the blending method is assumed to be the most convenient. Soft rubber or polymers with specific functionalities can be directly blended with epoxy resin to achieve reformation.

Using the network, straight-chain PU polymers, and reformed epoxy resin, an interpenetrating polymer network (IPN) is established to achieve a "structure lock-in" by the interpenetrating covalent bonds, thereby preventing phase separation from occurring during the polymer blending process. A number of studies have adopted this blending method and obtained effective results. By contrast, few studies have verified whether interpenetrating covalent bonds are generated in IPNs to reduce phase separations. Nevertheless, the IPN preparation method addresses the issue of phase separation while maintaining favorable properties in all aspects, achieving reformation.

The broad definition of IPN is the combination of two or more polymer networks [1]. The optimal blend is obtained by interpenetration and entanglement between polymer chains. Currently, this type of

*Corresponding author: Hsien-Tang Chiu, Department of Materials Science and Engineering, National Taiwan University of Science and Technology, Taipei, Taiwan, Tel: +886 22733 3141; E-mail: xyhsu.0879@ttri.org.tw

Received July 25, 2015; Accepted October 12, 2015; Published October 19, 2015

Citation: Chiu HT, Hsu XY, Yang HM, Yu YT, Ciou YS (2015) The Influence that the Blend Process has on the Hardening Behavior of a PU/Epoxy Resin System. J Textile Sci Eng 5: 215. doi:10.4172/2165-8064.1000215

Copyright: $\odot 2015$ Chiu HT, et al. This is an open-access article distributed under the terms of the Creative Commons Attribution License, which permits unrestricted use, distribution, and reproduction in any medium, provided the original author and source are credited. 
special polymer blending method is the only effective measure that can be employed to blend thermosetting polymers.

Because the IPN comprises two interconnected network structures that affect the size, shape, and composition of phase domains in the IPN [1], their morphological compositions influence the physical and mechanical behaviors of polymers in the IPN. In multicomponent polymer systems, a uniform mixture and homogeneous blends can be attained using methods such as polymer blending, grafts [2], and copolymers [3,4]. Similarly, in the IPN, interpenetrating covalent bonds and entanglement polymer chains are used to achieve the ultimate goal of molecular mixing of the multicomponent polymer system [5].

The encapsulation technique has been developed for over 40 years. The fabricated capsule consists of core and shell materials. Because the core, shell, and encapsulation methods used differ, the shape, size, and structure of the capsule also differ significantly. Generally, capsules with less than a $1 \mu \mathrm{m}$ diameter are called nano-microcapsules, and those with a diameter ranging between $1 \mu \mathrm{m}$ and $1 \mathrm{~mm}$ are called microcapsules. Because, the capsule size cannot be strictly limited during the manufacturing process, capsules with a diameter of several millimeters can also be classified as microcapsules. Therefore, microcapsules refer to capsule particles with a diameter ranging from several micrometers to several millimeters. The technique for microcapsule fabrication is known as microencapsulation [6].

Microencapsulation refers to a process where liquids, solids, and gases are surrounded using natural or synthesized polymer materials. The surrounding shell materials provide a physical barrier between the core and the external environment, thereby engendering new properties of the core. Microencapsulation can be applied to various fields, such as food products, textiles, cosmetics, papermaking, medicine, biotechnology, agriculture, and husbandry. Regarding its application to food products, microencapsulation has changed what was impossible into possible applications and simplified conventional techniques, thereby substantially contributing to increased technicality and high-value product development in the food industry [6].

The microencapsulation technique attracts interest because of the following characteristics [7]:

(1) The shell can protect matter that is sensitive to light, heat, humidity, acid, or alkali or prone to oxidization in air or dissolve in water. (2) Changing the shape or hydrophilic and lipophilic properties of matter can enhance its usability. (3) The shell protects against odors, colors, and toxicity. (4) The reaction components are insulated to control the release function by contacting the components for required reactions.

The encapsulation method comprises three types: (1) physical chemical methods, (2) chemical methods, and (3) mechanical methods. Because the adopted encapsulation method and coating material differs, the size, shape, and strength of the prepared microcapsules also vary [8-10].

The thermal behavior and isothermal curing of parent phenolicurea oligomers and their corresponding blend with commercial epoxy resin was carried out in order to optimize the temperature for fabrication of glass fiber laminates.

\section{Experiment}

\section{Materials}

- $\quad$ L128E type epoxy resin (E) by the Core Precision Material
Co., Ltd.

- $\quad$ PN-23 type imidazole hardener $(\mathrm{H})$ by Taiso Commerce Inc.

- 50501 type polyurethane (U) by Nanya Resin Company.

\section{Steps}

This study employed the following two feeding methods: $\mathrm{P}+\mathrm{H}+\mathrm{E}$ and $\mathrm{E}+\mathrm{H}+\mathrm{U}$. The ratio of $\mathrm{E}$ to $\mathrm{U}$ was $7: 3$. The amount of $\mathrm{H}$ added was dependent on the quantity of E. Separate steps with various added amounts and preprocessing times are shown below.

1. In the proportion experiment of $\mathrm{U}+20 \mathrm{phr} \mathrm{H}+\mathrm{E}, 14.4 \mathrm{~g}$ of $\mathrm{U}$ and $6.72 \mathrm{~g}$ of $20 \mathrm{phr} \mathrm{H}$ were weighed and mixed through revolution and rotation for $4 \mathrm{~min}$. After being uniformly mixed, the mixture was combined with $11.2 \mathrm{~g}$ of $\mathrm{E}$ and again mixed through revolution and rotation for $2 \mathrm{~min}$ to obtain the first sample group.

2. Based on the different feeding sequence of $\mathrm{E}+20 \mathrm{phr} \mathrm{H}+\mathrm{U}$, $11.2 \mathrm{~g}$ of $\mathrm{E}$ and $6.72 \mathrm{~g}$ of $20 \mathrm{phr} \mathrm{H}$ were weighed and mixed through revolution and rotation for $4 \mathrm{~min}$. Subsequently, $14.4 \mathrm{~g}$ of $\mathrm{U}$ was added to the mixture, which was mixed through revolution and rotation for 2 min. The product formed the second sample group.

3. Regarding the preprocessing experiments of $\mathrm{U}+20 \mathrm{phr} \mathrm{H}+\mathrm{E}$, $14.4 \mathrm{~g}$ of $\mathrm{U}$ and $6.72 \mathrm{~g}$ of $20 \mathrm{phr} \mathrm{H}$ were weighed and mixed through revolution and rotation for $4 \mathrm{~min}$. The uniformly distributed mixture was quartered, with each part amounting to $5.28 \mathrm{~g}$. The four parts were preprocessed in an oven at $50^{\circ} \mathrm{C}$ for $0,5,10$, and $20 \mathrm{~min}$. Subsequently, each part was combined with $11.2 \mathrm{~g}$ of $\mathrm{E}$ and mixed through revolution and rotation for $2 \mathrm{~min}$

4. Regarding the $\mathrm{U}+\mathrm{H}+\mathrm{E}$ experiment with varying proportions of $\mathrm{H}, 20,30$, and $40 \mathrm{phr} \mathrm{H}$ and $\mathrm{U}$ were mixed and preprocessed according to the process used for Step 3. The mixture was first preprocessed at $50^{\circ} \mathrm{C}$ for $10 \mathrm{~min}$, combined with $11.2 \mathrm{~g}$ of $\mathrm{E}$, and then mixed through revolution and rotation for $2 \mathrm{~min}$.

\section{Instruments}

Digilab FTS-1000 was used to perform Fourier transform infrared spectroscopy (FTIR). PU and epoxy resin were separately and uniformly mixed with the hardener. Tetrahydrofuran (THF) was diluted to $5 \%$ or less and dripped onto the $\mathrm{KBr}$ pellet. THF was removed by heating the pellet sample in an oven at $30^{\circ} \mathrm{C}$ for $1 \mathrm{~h}$. The same samples were separately heated at $30^{\circ} \mathrm{C}, 50^{\circ} \mathrm{C}, 70^{\circ} \mathrm{C}, 90^{\circ} \mathrm{C}, 110^{\circ} \mathrm{C}, 130^{\circ} \mathrm{C}, 150^{\circ} \mathrm{C}$, $170^{\circ} \mathrm{C}, 190^{\circ} \mathrm{C}$, and $210^{\circ} \mathrm{C}$ for $20 \mathrm{~min}$ and then analyzed using FTIR. In the atmospheric environment, the scans were repeated 20 times at a resolution of 8 and ranging between $450 \mathrm{~cm}^{-1}$ and $4000 \mathrm{~cm}^{-1}$.

Perkin Elmer DSC 4000 was used to conduct differential scanning calorimetry (DSC).

Condition 1: 5 to $10 \mathrm{mg}$ samples were placed on the aluminum plate and heated from $30^{\circ} \mathrm{C}$ to $200^{\circ} \mathrm{C}$ at a heating rate of $2^{\circ} \mathrm{C}$ per min. The onset temperature and exothermic maximum temperature were recorded.

Condition 2: 5 to $10 \mathrm{mg}$ samples were placed on the aluminum plate at a fixed temperature. The enthalpy of endothermic and exothermic reactions was observed and recorded.

A peeling strength test was performed based on the CNS 5812 T-peel test. The cut aluminum plate size, with a length and width of approximately $300 \mathrm{~mm}$ and $25 \mathrm{~mm}$, is shown in Figure 1. The samples were coated onto the aluminum plate and cured at $160^{\circ} \mathrm{C}$ for $30 \mathrm{~min}$. 


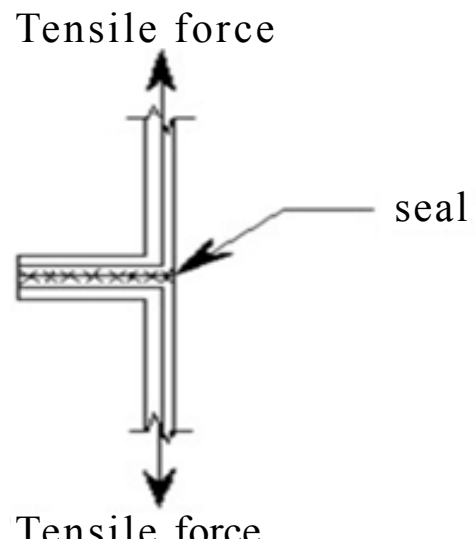

Figure 1: T-peel test.

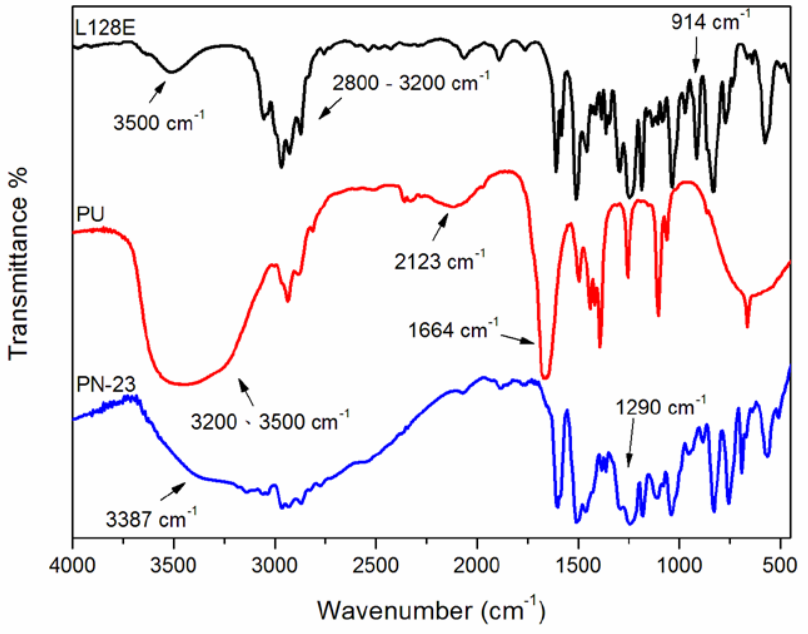

Figure 2: FTIR spectra of L128E, PU, and P.N-23

TA Instrument, Inc. TMA Q400 was used to conduct thermomechanical analysis (TMA). The specimen shape was a square, with a side length of approximately $10 \mathrm{~mm}$ and a thickness of less than 5 $\mathrm{mm}$. Using the "expansion" mode in the atmospheric environment, the thermal expansion curve was measured under a temperature increase from $30^{\circ} \mathrm{C}$ to $200^{\circ} \mathrm{C}$ at a rate of $5^{\circ} \mathrm{C}$ per min, with a $1-\mathrm{Hz}$ frequency and $0.05 \mathrm{~N}$ force.

\section{Results and Discussion}

Figure 2 shows the FTIR spectra of L128E, PU, and PN-23. L128E indicates the characteristic absorption peaks of the epoxy group at 914 $\mathrm{cm}^{-1} ; \mathrm{CH}, \mathrm{CH}_{2}$, and $\mathrm{CH}_{3}$ at 2800 to $3200 \mathrm{~cm}^{-1}$; and $\mathrm{O}-\mathrm{H}$ at $3500 \mathrm{~cm}^{-1}$. $\mathrm{PU}$ indicates the characteristic absorption peaks of $\mathrm{C}=\mathrm{O}$ at $1664 \mathrm{~cm}^{-1}$; the isocyanate group $(-\mathrm{N}=\mathrm{C}=\mathrm{O})$ at $2123 \mathrm{~cm}^{-1}$; and $\mathrm{N}-\mathrm{H}$ and $\mathrm{O}-\mathrm{H}$ at 3200 to $3500 \mathrm{~cm}^{-1}$. PN-23 indicates the characteristic absorption peaks of imidazole C-N at $1290 \mathrm{~cm}^{-1}$ and N-H at $3387 \mathrm{~cm}^{-1}$.

\section{Analysis and determination of the epoxy resin and imidazole reaction structure}

Figure 3 shows the FTIR spectrum of L128E/PN-23 blended at varying temperatures. The invariable absorption peak of this reaction is $573 \mathrm{~cm}^{-1}$. Using this absorption peak as the standard overlap peak, when the temperature increases gradually, the characteristic absorption peaks of the epoxy group at $914 \mathrm{~cm}^{-1}$ and $\mathrm{C}-\mathrm{O}$ at $1084 \mathrm{~cm}^{-1}$ are reacted, disappearing gradually. According to the dissipating characteristic absorption peaks at these two positions, the imidazole hardener and epoxy resin can be considered to undergo gradual ring-opening polymerization. In addition, the heterocycle resonance of imidazole is destroyed during polymerization, resulting in a stronger absorption peak of $\mathrm{C}=\mathrm{C}$ at $1650 \mathrm{~cm}^{-1}$. Therefore, the imidazole hardener and epoxy resin can be verified to polymerize gradually, as shown in Figures 4 and 5 .

Figure 6 shows the FTIR spectrum of PU/PN-23/L128E blended at varying temperatures. During the blending process, $\mathrm{PU}$ and $\mathrm{PN}$ 23 are first mixed through revolution and rotation, combined with L128E, and then subjected to further mixing. As shown in Figure 6, the invariable absorption peak of this reaction occurs at $571 \mathrm{~cm}^{-1}$. Using this absorption peak as the standard overlap peak, when the temperature increases gradually, the characteristic absorption peaks of the epoxy group at $914 \mathrm{~cm}^{-1}$ and $\mathrm{C}-\mathrm{O}$ at $1079 \mathrm{~cm}^{-1}$ react and dissipate gradually. According to the dissipating characteristic absorption peaks at these two positions, the imidazole hardener and epoxy resin can be inferred to undergo gradual ring-opening polymerization. The PU $\mathrm{C}=\mathrm{O}$ characteristic absorption peak occurs at $1667 \mathrm{~cm}^{-1}$. The decreasing epoxy group verifies that the addition of PU does not influence the reaction between imidazole and the epoxy group.

The softening point, also known as the deflection temperature,

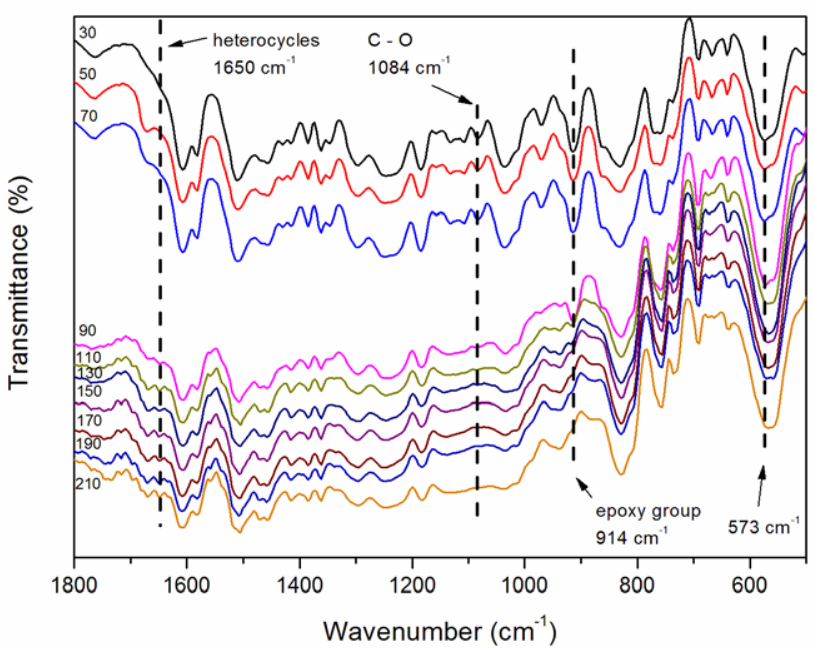

Figure 3: FTIR spectrum of L128E/PN-23 blended at varying temperatures.

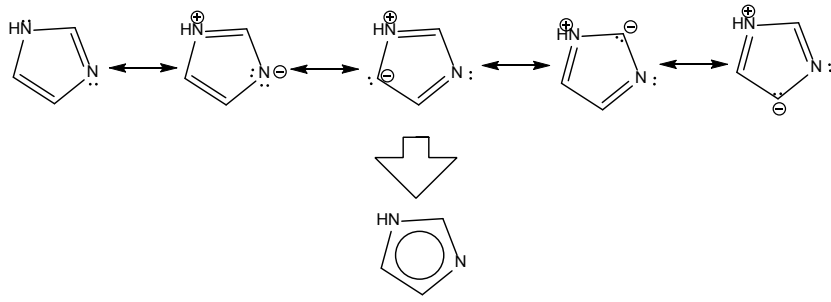

Figure 4: Resonance structure of imidazole. 


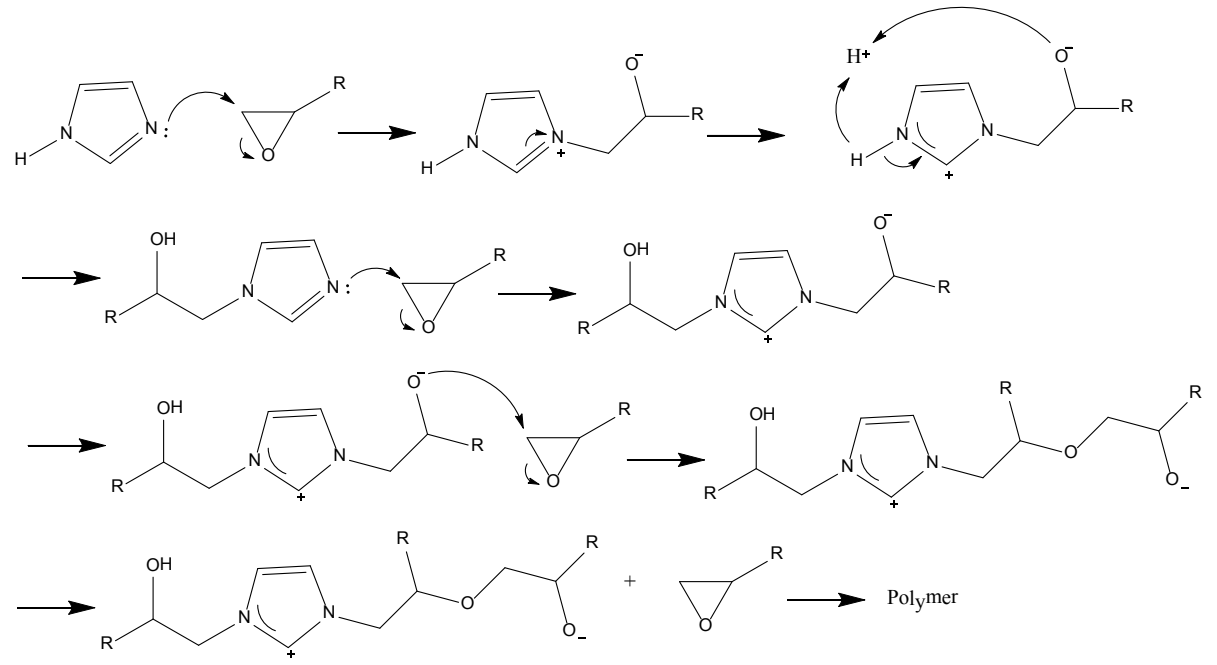

Figure 5: The reaction structure of imidazole and epoxy resin.

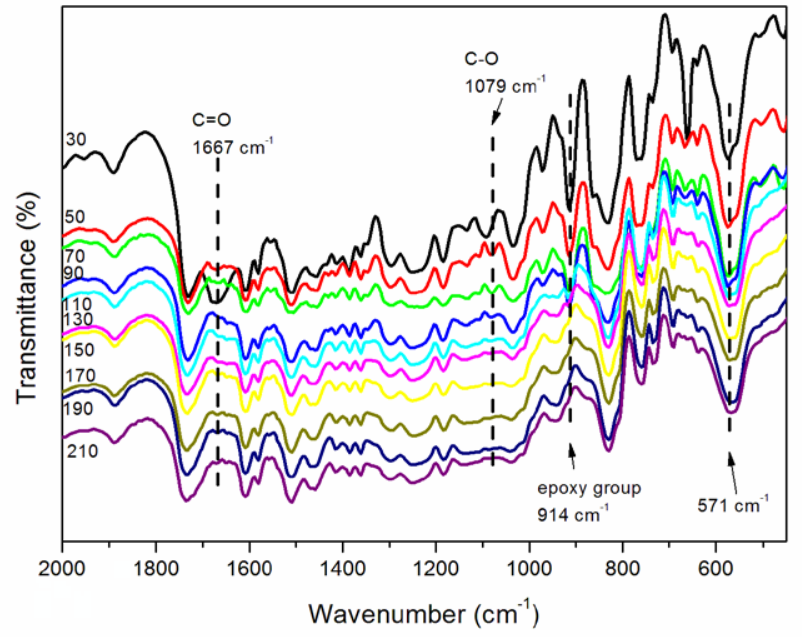

Figure 6: FTIR spectrum of PU/PN-23/L128E blended at varying temperatures.

represents the temperature where a polymer material softens with reduced mechanical performance during heating. Samples are commonly heated under loads when tested. When the sample deformation value reaches a specific limit, the corresponding temperature is measured. Figure 7 shows a TMA graph of PU, where the size change of PU increases gradually with the temperature. The softening point occurred at $105.2^{\circ} \mathrm{C}$.

\section{Analysis and determination of the influence that differing processing procedures have on reaction rates}

Figure 8 shows the DSC graph of L128E, PU, and PN-23 blended using varying processing procedures. As shown in Figure 8, the onset temperature is $84.8^{\circ} \mathrm{C}$, the delta $\mathrm{H}$ is $-260.7 \mathrm{~J} / \mathrm{g}$, and the maximum exothermic peak is $97.5^{\circ} \mathrm{C}$ in the $\mathrm{E} / \mathrm{H}$ system. The onset temperature is $80.4^{\circ} \mathrm{C}$, the delta $\mathrm{H}$ is $-307.7 \mathrm{~J} / \mathrm{g}$, and the maximum exothermic peak is $105.4^{\circ} \mathrm{C}$ in the $\mathrm{E} / \mathrm{H} / \mathrm{U}$ system. The onset temperature is $80.9^{\circ} \mathrm{C}$, the delta $\mathrm{H}$ is $-313.3 \mathrm{~J} / \mathrm{g}$, and the maximum exothermic peak

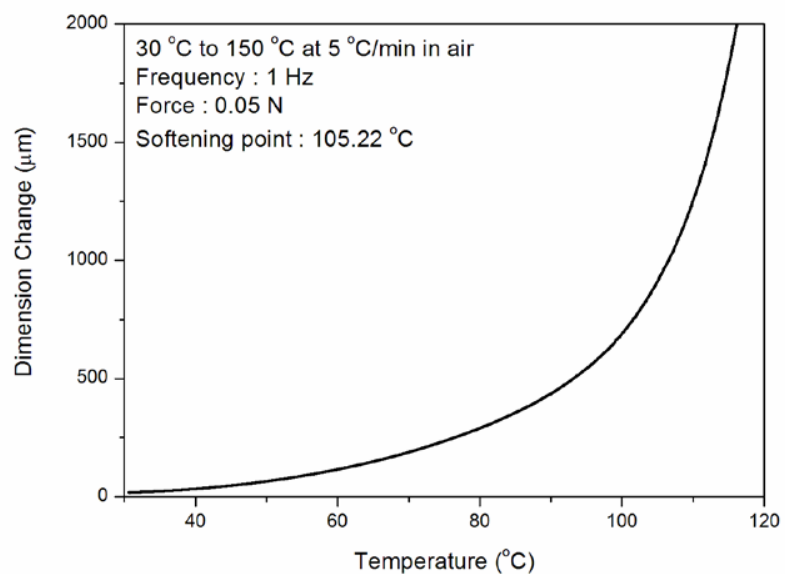

Figure 7: TMA graph of PU.

is $107.2^{\circ} \mathrm{C}$ in the $\mathrm{U} / \mathrm{H}$ system. These results show that adding $\mathrm{PU}$ to the system reduces the onset temperature and increases the delta $\mathrm{H}$ area and maximum exothermic peak. This is possibly because the polymerization temperature of PU is lower than that of the epoxy resin/imidazole system, thereby reducing the onset temperature. The increase of the delta $\mathrm{H}$ area results from the addition of $\mathrm{PU}$ polymerization. The peculiar phenomenon of an increasing maximum exothermic peak may be caused by the faster polymerization reaction of PU compared to that of the epoxy resin/imidazole system. Because PU embeds a portion of imidazole during polymerization to fabricate microcapsules, when the temperature is increased to the onset point of the epoxy resin/imidazole system, the imidazole embedded in PU does not react with epoxy resin until the $\mathrm{PU}$ reaches its softening point. Thus, the maximum exothermic temperature increases.

Figures 9-11 shows DSC thermostatic graphs of differing processing procedures at various temperatures. According to the maximum exothermic peak temperature in Figure 8, several temperature points 
Citation: Chiu HT, Hsu XY, Yang HM, Yu YT, Ciou YS (2015) The Influence that the Blend Process has on the Hardening Behavior of a PU/Epoxy Resin System. J Textile Sci Eng 5: 215. doi:10.4172/2165-8064.1000215

Page 5 of 7

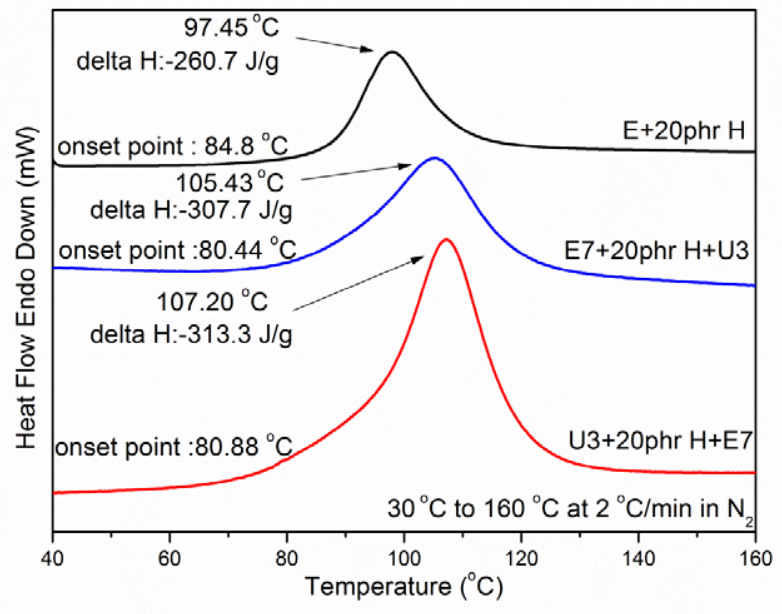

Figure 8: DSC graph of $\mathrm{L} 128 \mathrm{E}, \mathrm{PU}$, and $\mathrm{PN}-23$ blended using varying processing procedures.

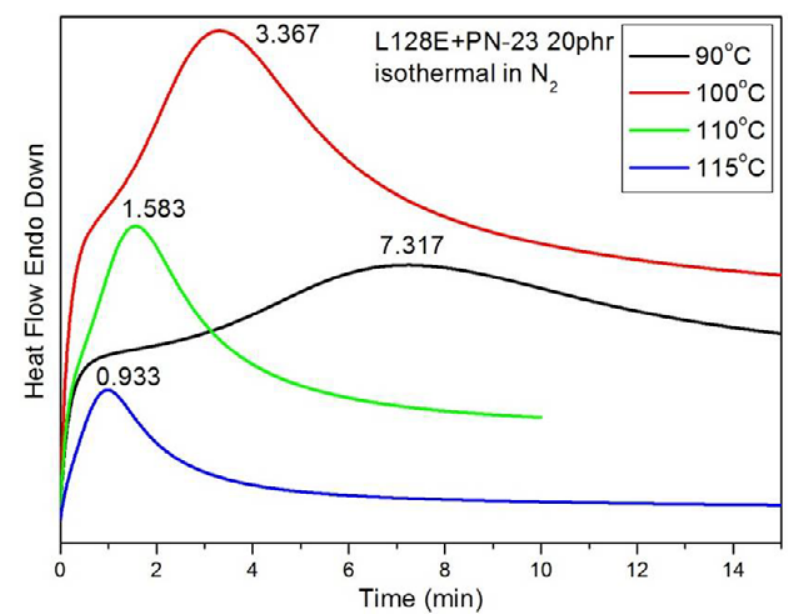

Figure 9: DSC thermostatic graph of L128E/PN-23 blended at various temperatures.

were identified as fixed temperatures. Figure 9 is a DSC thermostatic graph of L128E/PN-23 blended at various temperatures, where each curve possesses one reaction exothermic peak. A higher fixed temperature results in a shorter reaction time and vice versa. Figure 10 is the DSC thermostatic graph of L128E/PN-23/PU blended at various temperatures, where each curve possesses only one reaction exothermic peak, similar to that of Figure 9.

Figure 11 is the DSC thermostatic graph of PU/PN-23/L128E blended at various temperatures, where two reaction exothermic peaks occur on the curve with higher temperatures. The reaction time also increases compared to that shown in Figures 9 and 10. Thus, this study infers that the reaction between imidazole and epoxy resin is delayed because of the imidazole embedded in PU. When the temperature is fixed at $105^{\circ} \mathrm{C}$, a shoulder appears before the maximum exothermic temperature. When the temperature is fixed at $110^{\circ} \mathrm{C}$, the original shoulder of $105^{\circ} \mathrm{C}$ becomes the maximum exothermic temperature, whereas the maximum exothermic temperature of $105^{\circ} \mathrm{C}$ declines.
Based on this situation, we infer that although PU forms a protective layer by embedding imidazole, $\mathrm{PU}$ continuously releases the hardener during polymerization, thereby generating the shoulder. Using the maximum exothermic peak points of Figures 9-11 as the gel time, Figure 12 shows the relationship between the logarithmic gel time (s) and the absolute temperature scale $(\mathrm{K} / 1000)$.

Figure 12 displays the influence that varying processing procedures have on reaction rates. The results shown in Figure 12 indicate that higher temperatures and shorter reaction times exist between the hardener and epoxy resin under differing processing procedures and conditions. As shown in Figure 12, the reaction rates of the $\mathrm{E} / \mathrm{H}$ system and the $\mathrm{E} / \mathrm{H} / \mathrm{U}$ system are extremely similar, whereas the $\mathrm{U} / \mathrm{H} / \mathrm{E}$ system provides a reaction rate that differs significantly from that of the other two systems. This is because the $\mathrm{E} / \mathrm{H} / \mathrm{U}$ system blends epoxy resin and imidazole before adding PU. Thus, the amount of imidazole embedded in PU is limited, reducing the likelihood of fabricating microcapsules.

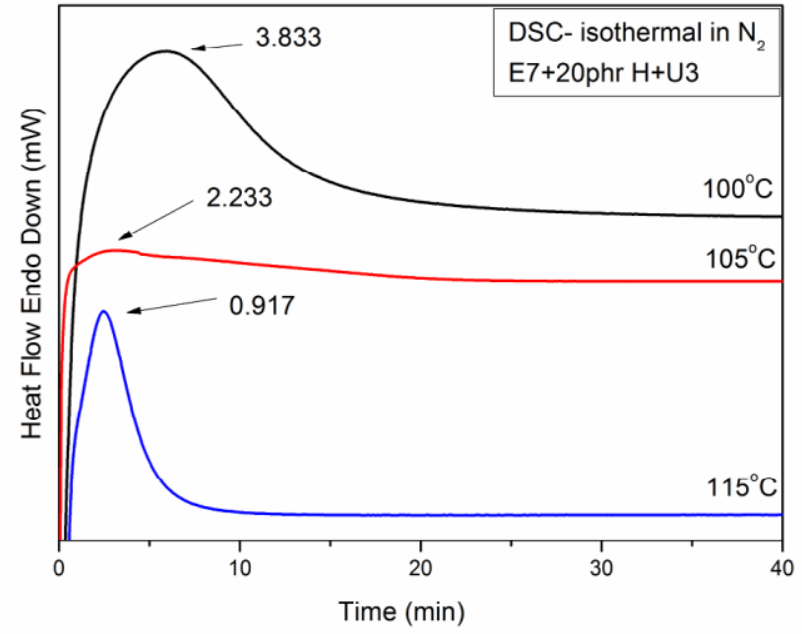

Figure 10: DSC thermostatic graph of L128E/PN-23/PU blended at various temperatures.

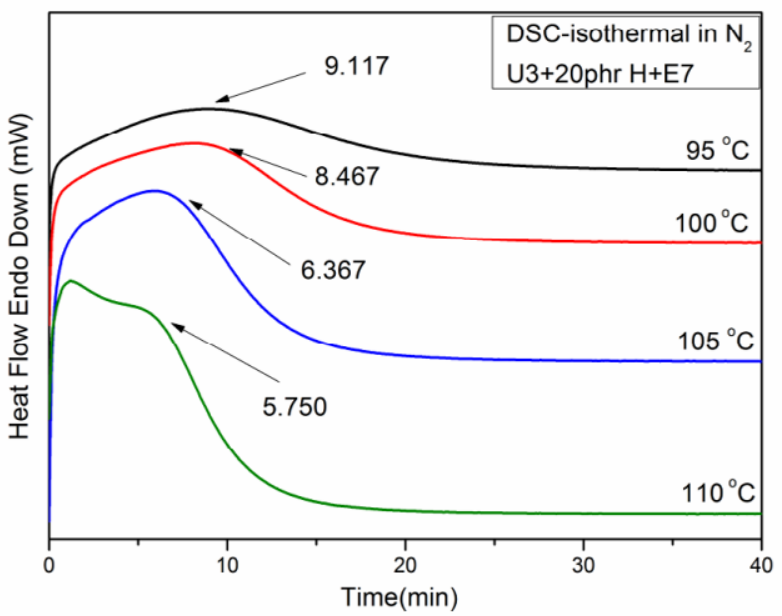

Figure 11: DSC thermostatic graph of PU/PN-23/L128E blended at various temperatures. 


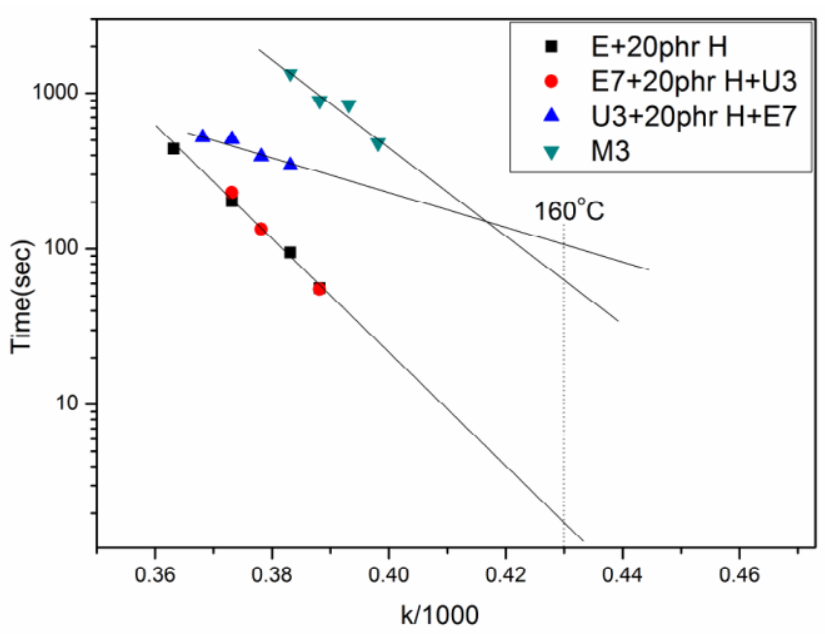

Figure 12: Influence of differing processing procedures on the reaction rates.

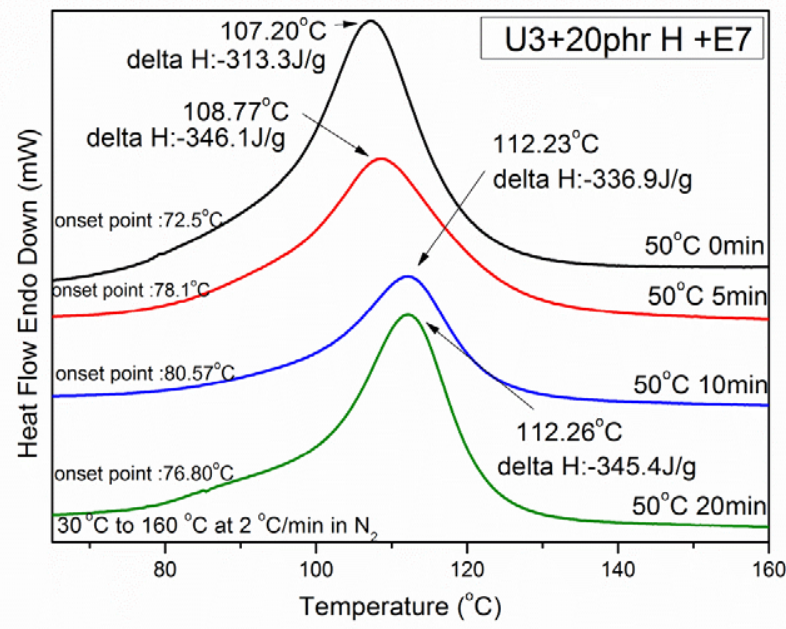

Figure 13: DSC graph of preprocessed $\mathrm{PU} / 20 \mathrm{phr} \mathrm{PN}-23$ blended at $50^{\circ} \mathrm{C}$ for differing durations before mixing with L128E.

By contrast, the U/H/E system blends PU and imidazole before adding epoxy resin; thus, additional imidazole is embedded in PU, resulting in a higher likelihood of fabricating microcapsules compared to the $\mathrm{E} / \mathrm{H} / \mathrm{U}$ system. Therefore, the reaction rate of the $\mathrm{U} / \mathrm{H} / \mathrm{E}$ system differs.

Moreover, the slope of the reaction rate of the same hardener should be almost identical. However, the reaction rate slope of the $\mathrm{U} / \mathrm{H} / \mathrm{E}$ system does not correspond with that of the $\mathrm{E} / \mathrm{H}$ and $\mathrm{E} / \mathrm{H} / \mathrm{U}$ systems and M3 [11]. Two possible reasons for this phenomenon may exist. (1) The PU polymerization involvement influences the reaction rate between epoxy resin and imidazole. However, according to the FTIR spectra of Figures 3 and 6, PU does not participate in the reaction of epoxy resin with imidazole; thus, this reason can be eliminated. (2) Microcapsules of PU-coated imidazole react with epoxy resin after blending. Incomplete coating of the microcapsule results in imidazole release at lower temperatures, thereby reducing the reaction rate. Thus, subsequent experiments have preprocessed (prehardened) PU to improve the coating and release mechanisms, and examined the influence that increasing hardeners has on the physical property of the hardener [12].

\section{Analysis and determination of the influence that differing processing methods have on reaction rates}

Figure 13 is a DSC graph of preprocessed PU/20 phr PN-23 blended at $50^{\circ} \mathrm{C}$ for differing durations before being mixed with L128E, where the onset temperature of $\mathrm{PU}$ without preprocessing and that with preprocessing at $50^{\circ} \mathrm{C}$ for 5 min differ significantly. The onset temperature increases from $72.5^{\circ} \mathrm{C}$ (without preprocessing) to $78.1^{\circ} \mathrm{C}\left(50^{\circ} \mathrm{C}\right.$ for $\left.5 \mathrm{~min}\right), 80.6^{\circ} \mathrm{C}\left(50^{\circ} \mathrm{C}\right.$ for $\left.10 \mathrm{~min}\right)$, and $76.8^{\circ} \mathrm{C}$ $\left(50^{\circ} \mathrm{C}\right.$ for $\left.20 \mathrm{~min}\right)$, and the maximum exothermic peak increases from $107.2^{\circ} \mathrm{C}$ (without preprocessing) to approximately $112.2^{\circ} \mathrm{C}$. These results indicate that PU preprocessing influences the release status. In addition, the optimal preprocessing condition is $50^{\circ} \mathrm{C}$ for $10 \mathrm{~min}$.

Figure 14 is a peeling strength graph of preprocessed $\mathrm{PU} / 20 \mathrm{phr} \mathrm{PN}-$ 23 blended at $50^{\circ} \mathrm{C}$ for differing duration before being mixed and cured with $\mathrm{L} 128 \mathrm{E}$, where the $\mathrm{E}+\mathrm{H}$ system possesses an extremely weak peeling strength on the aluminum plate. This may result from the reaction of epoxy resin with imidazole reducing the adhesion of epoxy resin to solids. During the reaction of epoxy resin with imidazole, imidazole induces the ring opening of the epoxy group, fabricating the R-O-R ester group, rather than the $-\mathrm{OH}$ group, which is the most crucial group providing adhesion in epoxy resin. Thus, adhesion decreases, as shown in Figure 5. The addition of the PU system prevents imidazole from reacting with epoxy resin before the softening point of $\mathrm{PU}$ is reached because of the PU coating. This is employed because imidazole reacts with epoxy resin extremely rapidly at high temperatures, resulting in lower polymerization levels and greater $-\mathrm{OH}$ group retention.

Regarding the hardener content changes, the peeling strength of 20 and $30 \mathrm{phr} \mathrm{H}$ is stronger than that of pure PU. When the hardener content is increased to $40 \mathrm{phr}$, the peeling strength declines. This phenomenon may be caused by the following two reasons: (1) Chemical reaction: excessive imidazole is involved in the reaction, resulting in lower $-\mathrm{OH}$ content, thereby reducing adhesion. (2) Physical aggregation: because imidazole aggregation induces an uneven coating, certain parts cannot be effectively bridged with epoxy resin after hardening, thereby reducing the peeling strength.

\section{Conclusion}

The DSC analysis results indicate that differing processing

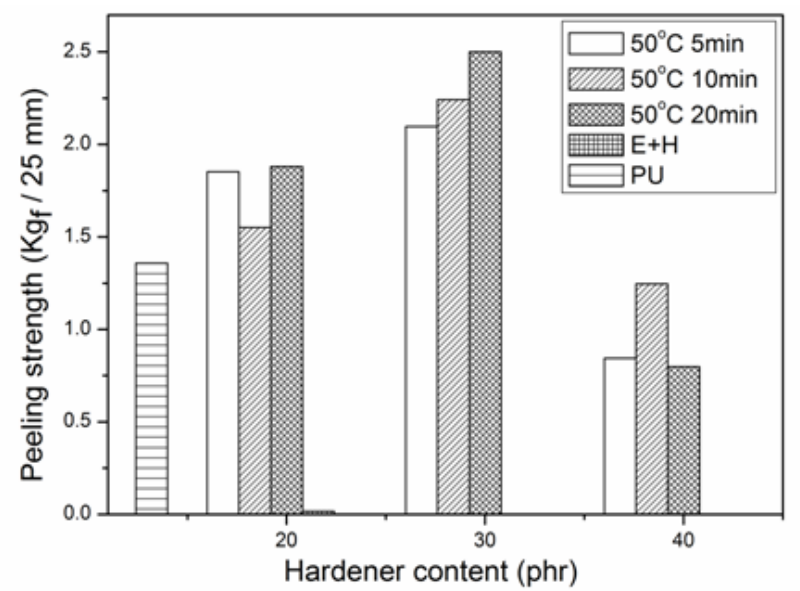

Figure 14: Peeling strength graph of preprocessed PU/20 phr PN-23 blended at $50^{\circ} \mathrm{C}$ for differing durations before being mixed and cured with L128E. 
Citation: Chiu HT, Hsu XY, Yang HM, Yu YT, Ciou YS (2015) The Influence that the Blend Process has on the Hardening Behavior of a PU/Epoxy Resin System. J Textile Sci Eng 5: 215. doi:10.4172/2165-8064.1000215

Page 7 of 7

procedures influence the latent hardening behavior and hardener embedding and release behaviors. This shows that pre-processing under varying conditions influences the latent hardening behavior and hardener embedding and release behaviors.

The optimal condition for preparing microcapsules through prepolymerization is $50^{\circ} \mathrm{C}$ for $10 \mathrm{~min}$. The peeling test results showed that the peeling strength of systems combined with PU was significantly higher than that of system without the addition of PU.

\section{Acknowledgments}

The authors are grateful to Taiwan Textile Research Institute for their financial support.

\section{Conflict of Interest}

We declare that we have no financial and personal relationships with other people or organizations that can inappropriately influence our work, there is no professional or other personal interest of any nature or kind in any product, service and/or company that could be construed as influencing the position presented in or the review of, the manuscript entitled, "The Influence that the Blend Process has on the Hardening Behavior of a PU/Epoxy Resin System".

\section{References}

1. Sperling LH (1981) Interpenetrating polymer networks and related materials. Plenum Press, New York.
2. Bucknall CB (1977) Toughened plastics. Applied Science Publishers Ltd London 359.

3. Noshay A, Mcgrath JE (1977) Block copolymers - overview and critical survey. Academic press, New York 516

4. Manson JA, Sperling LH (1976) Polymer Blends and Composites. New York, London 509.

5. Sperling LH (1978) Polymer Blend. Paul DR and Newman S (eds), Academic New York 2.

6. King AE (2009) Encapsulation of Lactic Acid Bacteria. Science Development 9: $36-41$.

7. Robert Langer, Joseph Kost (1983) Controlled-Release Technology: Bioengineering Aspects. Das KG, John Wiley and Sons, Canada, 225.

8. Nack H (1970) Microencapsulation Techniques, Applications and Problems Journal of the Society of Cosmetic Chemists 21: 85-98.

9. Sparks RE (1981) Microencapsulation in Encyclopedia of Chemical Technology John Wiley and Sons (3rdedn), New York 15: 470.

10. Kydonieus AF (1980) Controlled release technologies: methods, theory, and applications. CRC Press, Boca Raton, FL, USA.

11. Chen ZT (2011) Materials Science and Engineering. National Taiwan University of Science and Technology.

12. Raj MM, Raj LM (2012) Glass fiber reinforced composites of phenolic-ureaepoxy resin blends. Journal of Saudi Chemical Society 16: 241-246. 